\title{
Convergent evolution of health information management and health informatics
}

\section{A perspective on the future of information professionals in health care}

C. J. Gibson'; B.E. Dixon" ${ }^{2,3,4}$; K. Abrams ${ }^{5}$

${ }^{1}$ Schulich School of Medicine \& Dentistry, Western University, London, ON, CANADA;

2Richard M. Fairbanks School of Public Health, Indiana University, Indianapolis, IN, USA;

${ }^{3}$ Center for Biomedical Informatics, Regenstrief Institute, Inc., Indianapolis, IN, USA;

${ }^{4}$ Center for Health Information and Communication, Department of Veterans Affairs, Veterans Health Administration, Health Services Research and Development Service CIN 13-416, Richard L. Roudebush VA Medical Center, Indianapolis, IN, USA;

${ }^{5}$ Canadian College of Health Information Management, London, ON, CANADA

\section{Keywords}

Information management, informatics, competency-based education

\section{Summary}

Clearly defined boundaries are disappearing among the activities, sources, and uses of health care data and information managed by health information management (HIM) and health informatics (HI) professionals. Definitions of the professional domains and scopes of practice for HIM and HI are converging with the proliferation of information and communication technologies in health care settings. Convergence is changing both the roles that HIM and HI professionals serve in their organizations as well as the competencies necessary for training future professionals. Many of these changes suggest a blurring of roles and responsibilities with increasingly overlapping curricula, job descriptions, and research agendas. Blurred lines in a highly competitive market create confusion for students and employers.

In this essay, we provide some perspective on the changing landscape and suggest a course for the future. First we review the evolving definitions of HIM and HI. We next compare the current domains and competencies, review the characteristics as well as the education and credentialing of both disciplines, and examine areas of convergence. Given the current state, we suggest a path forward to strengthen the contributions HIM and HI professionals and educators make to the evolving health care environment.

\section{Correspondence to:}

Brian E. Dixon, MPA, PhD, FHIMSS

Regenstrief Institute

410 W. 10 th St.

Suite 2000

Indianapolis, IN, 46202 USA

Email: bedixon@regenstrief.org
Appl Clin Inform 2015; 6: 163-184

http://dx.doi.org/10.4338/ACI-2014-09-RA-0077

received: September 29, 2014

accepted: February 2, 2015

published: March 18, 2015

Citation: Gibson CJ, Dixon BE, Abrams K. Convergent evolution of health information management and health informatics - a perspective on the future of information professionals in health care. Appl Clin Inf 2015; 6: 163-184

http://dx.doi.org/10.4338/ACI-2014-09-RA-0077 


\section{Introduction}

Information and communication technologies (ICT) are transforming the health care system in both its practice and in the roles and knowledge required by health professionals. Over the past decade, there has been a significant increase in the adoption and use of e-health systems in the U.S. and Canada. National surveys in the U.S. estimate adoption of basic electronic health record (EHR) systems to be near 40\%, with adoption rates more than doubling from 2008-2012 [1-3]. In Canada, EHR adoption among primary care providers doubled, from 23\% in 2006 to $56 \%$ in 2012 [4]. Growth in adoption has been fueled by policy, such as the Health Information Technology for Economic and Clinical Health (HITECH) Act $[5,6]$ in the U.S.; by Canadian federal investment in Canada Health Infoway and various provincial e-health initiatives [7]; and by the belief that these ICT systems can improve the quality, safety, and efficiency of health services and delivery [8-10].

In parallel with increased adoption and use of these systems, a corresponding rise in new e-health workers who oversee the implementation and operations of the technology infrastructure has occurred [11]. These individuals work in a wide variety of roles, departments, and organizations but together they support the many processes and systems that capture, store, analyze, display, and transmit health data and information to the clinical and administrative professionals who need them. Estimates from the U.S. Bureau of Labor Statistics project sustained growth in e-health jobs over the next decade as information systems continue to be implemented, used, and inter-connected $[12,13]$. A recent Canadian report similarly projects both a human resource and skills shortage in e-health over the next five years, with $70 \%$ of the hiring requirements projected to be in information technology and health information management [14].

Two prominent disciplines have emerged from the mix of e-health workers now employed in health organizations - health informatics (HI) and health information management (HIM). While these disciplines have distinct ancestors, over time their definitions and scopes of practice have evolved. In this paper we describe how the disciplines have grown, analyze similarities and differences in the current marketplace, and present a forward-looking strategy towards a 'big tent' approach to education and training to support the evolving digital landscape.

\section{Definitions and Evolution of Health Information Professions}

In evolutionary biology, convergent evolution is the process whereby organisms that are not closely related, independently evolve similar traits as a result of having to adapt to similar environments or ecological niches [15]. The origins of HIM and HI differ; in this section we define each profession and review their beginnings.

\section{Health information management (HIM)}

As a profession, HIM dates its origins to 1928 with the formation of the Association of Record Librarians of North America (ARLNA) under the auspices of the American College of Surgeons (ACS) $[16,17]$. ARLNA grew out of efforts to standardize medical education and hospital practice to improve and evaluate the quality of patient care; the ACS recognized the need to establish a knowledgeable workforce to implement and manage standardized methods of collecting, storing, and retrieving patient data and records. The first annual meeting of ARLNA was held the following year, and initial steps were taken to institute a quarterly journal (now two journals, the Journal of AHIMA and Perspectives in Health Information Management), form a committee to develop a standardized course of study for medical record librarians, and set standards for registration and certification of its members. The organization subsequently changed its name to the American Association of Medical Record Librarians (AAMRL), the American Health Record Association in 1970, and most recently the American Health Information Management Association (AHIMA) in 1991 [16]. Canadian members split from the AAMRL to form their own association in 1942, the Canadian Association of Medical Record Librarians, and have undergone a similar transition - becoming the Canadian Health Record Association in 1972 and then the Canadian Health Information Management Association (CHIMA) in 2003 [17]. Although it began with a focus on the standardization and ment and health informatics. 
management of paper-based records within hospitals, today HIM focuses on the management of health information, "regardless of the medium or format" [18]. Current research and practice in HIM address the nature, structure, and translation of data into usable forms of information for advancing the health and health care of both individuals and populations.

\section{Health informatics (HI)}

Informatics is defined as the science of information, studying the representation, processing and communication of information by computers, humans, and organizations [19]. The term health informatics (HI) is often used synonymously (or confused) with a host of similar-sounding but distinct "adjectives" as noted by Hersh [20], including biomedical informatics (BMI), clinical informatics, and public health informatics. BMI has been broadly defined as an interdisciplinary field that studies and pursues the effective uses of biomedical data, information, and knowledge for scientific inquiry, problem solving, and decision making, driven by efforts to improve human health [21]. $\mathrm{BMI}$ is often conceived of as encompassing $\mathrm{HI}$ in addition to both clinical and public health informatics (see - Figure 1) [22]. Clinical informatics has been defined as the application and use of health information and technologies in the provision of health services, most often in the context of individual clinical care [23]. Public health informatics seeks to apply and use health information and technologies to improve population health, including the surveillance and prevention of disease as well as general health promotion [24]. In this paper, we define $\mathrm{HI}$ as the discipline concerned with the study and pursuit of effective uses of information, often aided by the use of technology, to improve health care delivery as well as individual and population health outcomes [20]. The field of HI studies and applies theories, methods, and processes for the generation, storage, retrieval, use, management, and sharing of health data and information; and HI builds on and contributes not only to the root informatics discipline but the related disciplines of computer and information sciences.

Like HIM, multiple professional organizations support the HI profession in the U.S. and Canada. The American Medical Informatics Association (AMIA) seeks to transform health care through science, education, and the practice of informatics, and represents HI educators, researchers, and professionals who work to design, develop, and evaluate e-health systems. AMIA was formed by the merger of three organizations in 1988: the American Association for Medical Systems and Informatics; the American College of Medical Informatics; and the Symposium on Computer Applications in Medical Care. AMIA hosts an annual symposium in which cutting edge research and development in informatics are presented, and the organization works year round on informatics education and professional initiatives.

$\mathrm{COACH}$, Canada's Health Informatics Association, represents health professionals interested in advancing $\mathrm{HI}$ including health informaticians, clinicians, chief information officers (CIOs), business analysts, vendors, information technology (IT) experts, and some HIM professionals. COACH was formed in 1975 by professionals and vendors in the medical industry to share ideas and efforts to enable Canadian health institutions to effectively use information technology and systems. The association's focus has since expanded to include not only information technology and systems, but also the effective use of health information for decision-making in support of "Taking Health Informatics Mainstream" [25].

The Healthcare Information and Management Systems Society (HIMSS) is a global, cause-based organization focused on better health through IT. HIMSS was first organized as the Hospital Management Systems Society (HMSS) in 1961 to promote the continual improvement of hospital management systems through organized programs of research, education, and professional practice. HMSS aligned itself with the American Hospital Association (AHA) given growing interest in health care management engineering that occurred in the 1950s, and it operated as an affiliate of AHA until 1993. During the 1970s and 1980s, the role of information systems in hospitals grew significantly, so in 1986 HMSS became HIMSS to offer AHA members with an affinity for IT/IS a home [26]. Currently HIMSS has over 52,000 members and includes an Ontario-based Canadian chapter of several hundred members $[27,28]$.

Medicine, nursing, and other allied health professions (e.g., pharmacy, dentistry) are also information-centric [29-32]. Clinicians must navigate a large corpus of knowledge from the biomedical sciences and an endless stream of new facts, new treatments, and new diagnostic tools. Clinicians ment and health informatics. 
must deal with information from an array of disparate sources, which they must process into decisions and prioritized tasks for the clinical team and patient [33-36]. The disciplines of HIM and HI increasingly support clinicians' as well as patients' health information needs. Furthermore, health information professionals are crucial members of the interdisciplinary and inter-professional teams that coordinate care of individuals across facilities and providers. They have the expertise in privacy and security of data; information sharing agreements, policies and procedures; data quality and integrity; data standards and definitions; records and content management through its lifecycle, clinical documentation and health information analysis that will allow the optimum utilization of data for health system use [29]. In the remainder of this article, we describe the evolution of the HIM and HI disciplines' educational credentialing and accreditation, core competencies, and job functions. While their origins differ, HIM and HI are increasingly supporting the acquisition, management, and use of health information to improve outcomes for individuals, populations, and organizations in similar ways.

\section{Education, Accreditation, and Credentialing}

Professional associations have played a critical role in the education and training of skilled HIM and HI practitioners from their beginnings. In both the U.S. and Canada, a formal delineation of HIM competencies has been developed and is used in guiding curriculum development in accredited programs as well as the creation of the national credentialing examinations. Competencies in $\mathrm{HI}$ have similarly been developed and applied for educational program accreditation, although efforts in $\mathrm{HI}$ are more recent and less widely adopted especially in health professional programs [37]. A complete summary of the various HIM and HI credentials currently available is presented in supplementary Appendix A.

Formal HIM educational programs exist in both the U.S. and Canada to prepare individuals to write credentialing examinations following receipt of an associates' (or college diploma in Canada; 2-3 year programs), baccalaureate (4 year programs), or Masters' degree. Programs are accredited based upon their adherence to a curriculum based on common standards, such as the Learning Outcomes for Health Information Management in Canada [38]. The Canadian College of Health Information Management (CCHIM) is a federally chartered national college that accredits HIM programs and oversees the credentialing of HIM professionals. Work is currently underway for the development and implementation of a Masters in HIM with a certification stream that would allow graduates to sit for the certification examination to become certified HIM professionals.

The U.S. has two separate organizations: one to accredit HIM and HI programs - the Commission on Accreditation for Health Informatics and Health Information Management Education (CAHIIM) - and one to certify individuals- AHIMA's Commission on Certification for Health Informatics and Information Management (CCHIIM). CAHIIM has established standards for HIM programs at the associates', baccalaureate, and Masters' degree levels, and for HI programs at the Masters' degree level. CCHIIM is an AHIMA commission dedicated to assuring the competency of professionals practicing health informatics and information management (HIIM). CCHIIM establishes, implements, and enforces standards and procedures for certification and recertification of HIIM professionals.

In addition to CAHIIM, there are several other organizations that accredit HI programs or individuals. HIMSS offers certifications for HI professionals but, unlike CAHIIM, it does not accredit academic programs. The International Medical Informatics Association (IMIA) has established competency criteria for HI professionals [39], which IMIA has applied as the basis for a pilot project on accreditation of HI programs. Four HI programs have completed the process and been awarded a 5-year accreditation. The programs are located at universities in Chile, Germany, Finland, and Taiwan [40].

Recently the American Board of Medical Subspecialties (ABMS) approved clinical informatics as a medical subspecialty [41]. Licensed physicians with a current ABMS Member Board certification in Canada or the U.S. may be eligible to become Board Certified in Clinical Informatics, provided they meet further practice or fellowship pathways [42]. The core content for clinical informatics includes four major categories: fundamentals, clinical decision making and care process improvement, 
health information systems, and leadership and management of change [43]. Over 400 doctors passed the first examination given in October 2013 [41]. Beginning in 2018, all applicants for certification in Clinical Informatics will have to complete a minimum of 24 months in an Accreditation Council for Graduate Medical Education (ACGME) accredited Clinical Informatics fellowship program [44]. Recognizing a need for an equivalent level of certification for informaticians who have equivalent competencies, AMIA recently launched an effort to establish core content in HI and certify those competencies across a wide range of clinical and IT professionals, who will be able to apply for advanced inter-professional informatics certification [45].

\section{Comparisons of HIM and HI}

Comparing HIM and HI education programs and credentials is challenging given their variety and evolution. Therefore we compared the fields of HIM and HI using the core competencies defined by the major accrediting and credentialing bodies, focusing on the essential knowledge domains and concepts. Using available competency white papers, program and curricular standards from accrediting bodies and published literature, we completed a comparison of competencies following a process similar to an academic program seeking external accreditation and harmonized, then synthesized and summarized, core competency lists through discussion and iterative revisions [38, 39, $43,46,47]$. Our professional expertise is derived from over 30 years cumulative experience of curriculum development for leading accrediting bodies. While some variations exist, we observe that current HIM and HI core competencies are more alike than different.

We identified six major domains and 34 knowledge concepts relevant to either HIM or HI (see - Table 1 and $>$ Figure 2). Both disciplines are well represented in every domain, and they share 28 $(82 \%)$ concepts. All of the knowledge concepts relevant to the domain of Computer and Information Sciences are shared, and nearly all but one concept in the Social and Behavioral Sciences are applicable to both disciplines. Variation lies in the other domains and primarily in the breadth or depth of application of knowledge.

HIM distinguishes itself in three main areas: 1) Education and Training; 2) Health Data Representation and Stewardship; and 3) Health Data Standards. The accrediting body for HIM explicitly contains concepts relevant to the design, execution, advocacy, and oversight of health information security, privacy, and compliance programs in health care organizations for clinical and non-clinical staff. While HI programs do not ignore these concepts, they do not emphasize them to the same degree as the HIM accrediting and credentialing sources. HIM programs further emphasize the need not just to be involved with, but also to lead, organizational education programs aimed at health care professionals, as well as consumers, on health information and how best to protect it. HIM programs provide a greater level of emphasis on applied knowledge for the concepts of data representation, data governance, and data standards. This emphasis is especially true in the associates' program requirements which emphasize coding classification. Whereas HI programs emphasize the theoretical underpinnings of data standards (e.g., ontologies, taxonomy) and clinical data representation, HIM programs focus on available coding systems and attendant standards, their internal structure, and their application to both billing and clinical documentation.

Informatics distinguishes itself in three areas: 1) Computer Science and System Design; 2) Statistics and Data Sciences; and 3) Socio-technical systems. Whereas HIM competencies focus on the implementation and management of EHR systems, HI standards emphasize the design, development and implementation of novel algorithms and applications across a broader range of health information systems. Programs and competencies in HI further emphasize the more technical aspects of systems, including the development of user interfaces as well as the development of backend systems that support information exchange between clinical applications. While HIM emphasizes basic statistics and interpretations of evidence-based medicine studies, HI standards emphasize a more robust mathematical foundation relevant to the computer and data sciences supporting activities such as programming, decision support logic, and machine learning. HI program standards often call for more advanced statistics, such as biostatistics, data mining, and biomedical research design. HI program standards further emphasize social-technical systems, focusing not only on usability of 
interactive health information systems, but also relevant applications areas such as clinical workflow, process modeling, and systems redesign.

While these distinctions exist in accreditation requirements and curricula, they may not always exist in practice. Both HIM and HI professionals are often involved in tasks such as end user education for privacy, security, and compliance as well as systems redesign efforts in health care organizations. These distinctions may therefore be historical remnants reflecting differences between 2-4 year undergraduate programs, mainly in HIM where applied knowledge is emphasized for specific classes of jobs, versus Masters' degree programs in the field of HI which tend to focus on the theoretical foundations of the HI sciences and applications of the more advanced information systems used in health care organizations.

\section{The Changing Landscape: The Drive for Evolutionary Change}

The accreditation, credentialing, and curricula documents we reviewed and summarized were all published in the last 2-3 years. The documents signify that HIM and HI professional associations recognize the accelerating pace of change within health care systems and have identified specific trends and forces that are shaping their roles and functions for the future. Joint task force work by AMIA and AHIMA has recognized a set of specific "EHR competencies" that concentrate on needed skills in the marketplace with no delineation of whether they are for HI or HIM professionals [48]. Furthermore, recent revisions to curricular competencies in both HI and HIM recognize a need for skills and knowledge that go beyond EHR development, procurement, implementation, and maintenance - the historical emphasis of HI professionals - and management of data collection and use, privacy and security, information governance, the data and information lifecycle, and information analysis - the historical emphasis of HIM professionals.

Evolution in core competencies and hence the appearance of new job roles and functions are in response to several key trends and forces shaping the HI and HIM professions, including:

- Broad scale semantic and functional interoperability supporting direct data capture, and capture and use of both highly structured data and completely unstructured data;

- The advent of digital ecosystem and learning health system approaches with implications for the growth and next generation of e-records;

- Greater emphasis on the health "system" and population health management which requires aggregation and analytics of e-records for improving patient outcomes, resource utilization, and provider allocation;

- Meaningful use, accountable care, activity-based funding models;

- The greater use of evidence-based decision making with an increasing need for skills in analyzing, mining, and interpreting data;

- Widely used clinical, mobile, and other personal health or home devices and applications with increasingly diverse implications for data quality, safety, and standardization - the Internet of Everything;

- Multi-jurisdictional and multi-institutional records and information governance;

- Consumers entering and using health information with implications for mapping to "common language", ownership / custodianship of the complete record, standardization of entered data, ensuring quality of data; and

- Genomics and the advent of personalized medicine with implications for the variety of data sources and uses.

\section{Evolving and Future Roles of HI and HIM Professionals}

As the HI and HIM skill set requirements shift from systems implementation to the application of health data and information systems to improve health delivery systems, new and evolving roles are emerging and the need for more specialized skills in the use, maintenance, protection, retrieval, and analysis of electronic data is increasing. Recent reports and white papers from leading HIM and HI associations describe these emerging roles and potential career paths of entry level through inter- 
mediate to master and expert professionals [49-51]. Career paths, much like competencies, are evolving into convergent areas where both HIM and HI skills and knowledge are applicable. Therefore, as with the competencies, we performed an extensive review of job titles and descriptions then synthesized the information ( Table 2). Literally hundreds of job descriptions were received from employers such as hospitals, governments, and community care agencies as well as identified through a search of on-line job posting sites. Similar job roles were determined by comparing the responsibilities outlined and the skills, education, or experience required as specified in the postings. Once grouped into like roles, these were a) amalgamated and identified as entry, intermediate, advanced, or mastery level (related to either education, experience, or both); b) defined as predominantly HI or HIM (for example if a specific credential or educational background was required); and c) matched to the appropriate competency/category profile.

The career matrix is organized horizontally along functional categories that describe the major practice areas in which HIM and HI professionals work and vertically along four levels of competency that distinguishes entry level careers from those of advanced and expert professionals ( $>$ Table 2). The matrix is modeled after those of CHIMA [49], AHIMA [50] and COACH [51, 52] to form an amalgamated version that encompasses both HI and HIM and enables comparison with past and future evolution of the professions.

Many categories may appear to be aligned predominantly with HIM or HI knowledge and skills. We have attempted to indicate which role may be historically identified with one discipline or the other and hence require the skills and/or certifications provided through that discipline, yet complexity lurks in each category as the organizations that collect, manage, and exchange health information evolve their workforces. For example, the category Information Management might naturally be associated with HIM given the sample careers and roles enumerated in the matrix (e.g. records administration, coding and classification, billing, activity based funding). However, recent studies and publications from both HIM and HI sources [53-58] make it evident that topics such as data quality are germane to both professions and indeed are practiced by each profession. Another example is the Information Technology/Systems category. While many roles in this category are predominantly technical in nature, some like Information Architect are more information-centric than technology-centric. Architects design not only technical interfaces and connections, but the flow of information through an organization. Therefore HIM and HI knowledge and skills are beneficial as information architects in health care must often navigate and understand complex clinical workflows to effectively design EHR and other IT systems that capture, store, or exchange information.

Other categories in this matrix more clearly represent the convergent pathways for HIM and HI. The category of Health Information Analytics and Research, for example, contains a fairly even mix of roles drawing upon HIM and HI competencies. The march to "Big Data" and analytics in health organizations underscores the need for a workforce that clearly understands health data and how they are generated, collected, stored, managed, presented, and used in the context of complex interdependent IT and human systems. The successful design, development, implementation, and usage of analytics applications in organizations will require the workforce to possess converging competencies that map across traditional boundaries between HIM and HI, including natural language processing (HI) and information governance (HIM), as well as competencies native to both, such as data quality, statistics, and presentation of analytical findings to stakeholders. HIM professionals often assume these roles in organizations because of their extensive knowledge of the origin and quality of the data and linkage between clinical, financial, and administrative databases. The HIM professional has a solid understanding of the complexity of the code sets and the data collection standards necessary to support the interpretation of the reports, while it may be the informatician who designs, develops, and implements the databases and representations to end users.

Within risk management the roles of privacy officer, information security manager, vice president of privacy and security are being filled by HIM in many instances as individuals in the workplace who have knowledge and experience in this domain, but increasingly these are included in HI curriculum. Privacy is a good example of an area in which a partnership or sharing of expertise across disciplines is advantageous. The complementary skill set of the HIM specialist, who can delineate the regulatory, legal and facility privacy needs for optimum systems, in concert with the informatician, who may develop and implement the architecture of the security system, provides the framework for a solid foundation to protect personal health information. And to support the ongoing ment and health informatics. 
training and education of both professions, teachers at the college and university level are needed to train individuals in these new skills.

The career matrix represents our best formulation of current, evolving and emerging careers at the time of publication, and therefore is not intended to be omniscient. Additional job titles and roles requiring HIM or HI knowledge and skills exist in health care organizations, but are not represented in the matrix. Given the velocity with which HIM and HI are evolving to meet the demands of real-world clinical and public health operations, the career matrix cannot include every role available. HI and HIM professionals must continue to adapt and evolve to meet the new challenges or others will willingly move into these new roles. It is clear that as we move forward in advancing healthcare technology and information systems, we need collaboration and cooperation across disciplines, not only within HI and HIM but also across the clinical sciences and administration.

\section{Discussion}

Although the origins of HI and HIM are distinct, the professions are converging in response to a variety of health care market forces. Changes in health care delivery (e.g., in where and who provides services), policies (e.g., privacy legislation, meaningful use of data, activity-based funding, adoption of technology), and information technologies (e.g., electronic records, mobile devices, data analytics, personal health records) are driving the two professions to revise curricula and competencies as well as create a common pathway for the road ahead.

In Canada, Conestoga College has developed a balanced undergraduate program in its Bachelor of Applied Health Information Science program that provides education in both HI and HIM [59]. Conestoga has recently received accreditation of its program through CCHIM which will allow graduates to write the HIM national certification examination upon graduation. Once the requisite experience has been accrued, graduates would be eligible to sit for the CPHIMS-CA certification examination. As well, CHIMA has recently introduced an external graduate pathway to the CHIM credential whereby a candidate with a minimum of an undergraduate degree in a related field and three years' work experience in HI or HIM can make application to write the credentialing exam without graduating from an accredited HIM program.

In the U.S., several institutions have established health informatics and information management or HIIM departments and programs: the University of Washington offers an executive-education style Masters in HIIM [60]; Louisiana Tech University has a HIIM department that offers a HIIM Bachelors and HI Masters [61]; and the University of Tennessee Health Science Center offers a combined Bachelors and Post-Graduate HIIM program [62]. Some HIIM programs and departments, including the University of Illinois-Chicago [63] and the Indiana University School of Informatics and Computing [64], offer undergraduate degrees in HIM and graduate degrees that focus on HI. Other schools, such as the Oregon Health \& Science University, offer distinct HIM and HI degree programs but, in which, HIM students take the same courses as HI students before specializing in their final year of study [65]. All of the U.S. programs align their undergraduate degrees with the RHIA credential, and most U.S. programs are accredited by CAHIIM. Depending on the graduates' career goals, advanced education can then focus on either HI or HIM theory.

The current cacophony of terms and program areas at diploma/associate, undergraduate, and graduate levels creates confusion for potential students as well as employers. Prospective students, and their parents, often ask about the difference between HIM and HI. The confusion can make student recruitment difficult, especially in a recovering economy where baccalaureate graduates are under-employed or unemployed. Employers, on the other hand, tend to emphasize credentials over programs of study, sometimes inappropriately. This can create confusion when employers seek, for example, a chief clinical informatics officer but specify HIM certifications as a requirement for job applicants.

HI and HIM programs of the future should incorporate a balance of both professional curricular components (see $>$ Table 1), yet have the flexibility to allow for a specific concentration depending on local faculty expertise. As noted above, there is already some movement in this direction. With current faculty shortages and growing market demand in both areas, the ability to provide balanced HIIM programs will allow for a more fully rounded and highly desirable professional while leveragment and health informatics. 
ing human resources across academic programs and departments. Furthermore, balanced education supports current and evolving academic program accreditation standards from CAHIIM as well as CCHIM. Programs naturally wish to distinguish themselves in the market, which they could do based on concentrations within the larger 'big tent' of HIIM. For example, students could take a balanced set of "core" courses then choose to specialize in a wide array of HIIM subjects such as privacy, security, terminology, clinical decision support, etc. The core would prepare students to sit for generalist certification while the specializations would allow students to go deeper on areas that align with local faculty expertise as well as regional market needs.

Movement towards balanced HIIM education further suggests that existing professional certifications should also be revisited. Over the past $12+$ years, the marketplace has seen a rise in types of certifications offered (see supplementary Appendix A). In addition to those offered by the major professional societies, new certifications in subspecialties like health information exchange, operating rules administration, and electronic health records have emerged in the marketplace [66]. Such variety contributes to confusion among emerging professionals and employers alike. Moreover, many of these certifications reflect traditional views of distinct knowledge bases between HIM and HI. Therefore a shift towards HIIM means re-examining the need for so many certifications. Some certifications may need to be retired or merged, while others may need to be revamped to incorporate a wider, common knowledge base. Professional societies and academic programs should work together to re-examine existing certifications and their knowledge bases, discussing which ones are best suited to transition into the era of HIIM.

The HIM profession has been accrediting programs for decades, but this is a fairly recent trend in HI. IMIA's accreditation is fairly broad and flexible in terms of competency requirements in its pilot programs. As the emphasis on computer science is stronger in Europe, IMIA's competency requirements may have to stay at a broader focus to suit an international accrediting body. Canadian HI programs, predominantly university based with many at the graduate level, have shown a reluctance to move to accreditation as they do not want to be held to a prescribed curricula. U.S. based HI programs are just beginning their pathway towards accreditation of programs by CAHIIM and of individuals through either the ABMS or the future AMIA inter-professional certification process. While accreditation does provide a standardized template of what is considered "core" content, programs are able to and encouraged to go above and beyond the minimum requirements and may specialize or extend any of the learning content items according to their own desire. Students want to attend accredited programs and have the ability upon graduation to become certified; students want an assurance that they will have the skills necessary to perform in their future jobs. Employers want assurances of skills and knowledge to step in and rapidly demonstrate competence in these new roles and jobs. Many jobs currently go unfilled due to the lack of skilled workers or are filled with individuals who lack the specific skills and training for the job [14]. If training is too individualized, programs may be training for a narrow set of jobs versus the larger market needs.

The HIM and HI professions are evolving, yet some current workers are entrenched in thinking themselves as "islands of knowledge" rather than taking an expanded view of their work. New graduates, particularly with the new learning outcomes and training in HIIM, may be more flexible and ready to participate in a culture of change and technology that is moving the professions forward. Associations have joined forces to work on specific projects $[14,38,48]$ but then tend to go their separate ways to put the information gathered into action. Together the associations and professional societies need to bring greater awareness of their skills, knowledge, and impact on the health system and provide a stronger public voice for awareness of the professions, lobbying efforts (for example as in the recent delay of ICD-10 implementation by the U.S. Congress and the impact on health services delivery and costs), and in policies related to information governance, sharing, and protection.

\section{Conclusions}

The ongoing implementation, maturation, and use of electronic health information systems require a complementary and overlapping skill set of competent HIM and HI professionals to support these systems in practice, making it difficult to continue to separate the two professions as distinctly dif-

C) Schattauer 2015 C. J. Gibson, B.E. Dixon, K. Abrams: Convergent evolution of health information management and health informatics. 
ferent. Colleges and universities are developing curricula and delivering programs to provide a balanced HIIM professional. New roles in health analytics, privacy, risk and change management require a more diverse skill set and understanding of the health system, biomedical sciences, information technologies, and principles of information management. As the workplace seeks and demands these new professionals, will the two professions and various associations and accrediting bodies work complementarily or continue to work in silos and at cross-purposes? A number of questions remain to be answered regarding research agendas in each field, the value and role of college versus undergraduate versus graduate degree education, and the place of practice versus theory in these disciplines. Limited human and financial resources are currently spent on independently trying to advance the two professions separately, yet we see that they are actually beginning to converge in their evolutionary development. Working together can likely accomplish more than working apart, for example, the sharing of knowledge on curriculum development, accreditation policies and procedures, and credentialing examinations.

\section{Conflict of Interest}

CJG serves as a university liaison for the College of Education and Professional Practice and was past chair of CHIMA. BED is a member of the HIMSS Distance Education Committee, which provides strategic guidance to HIMSS on its educational programming as well as the CPHIMS and CAHIMS certifications. KA is the Vice President of CCHIM, which is responsible for accreditation and certification of HIM professionals in Canada.

\section{Human Subjects Protections}

No human subjects were involved in this project. 


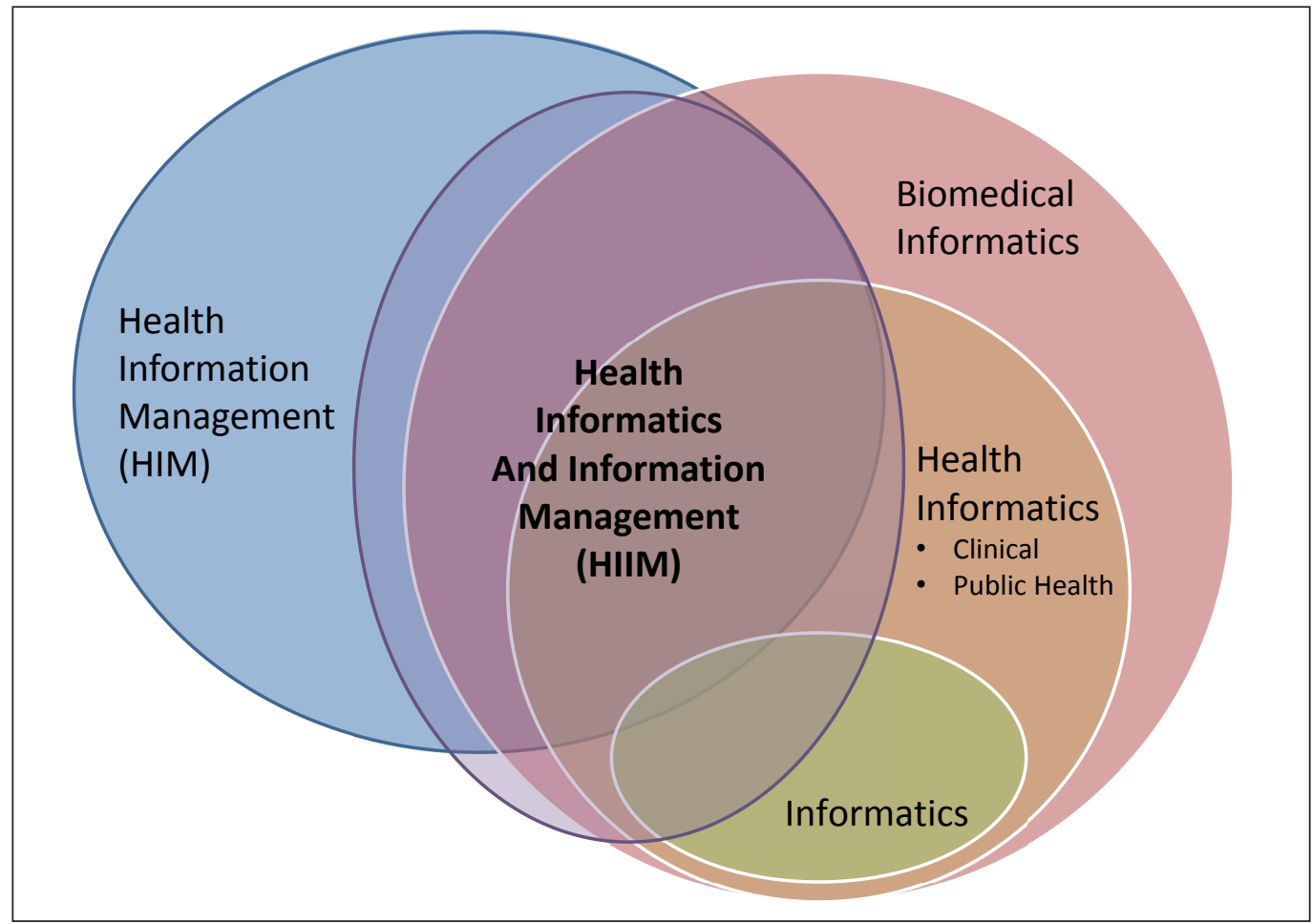

Fig. 1 Relationship of informatics and health information management disciplines.

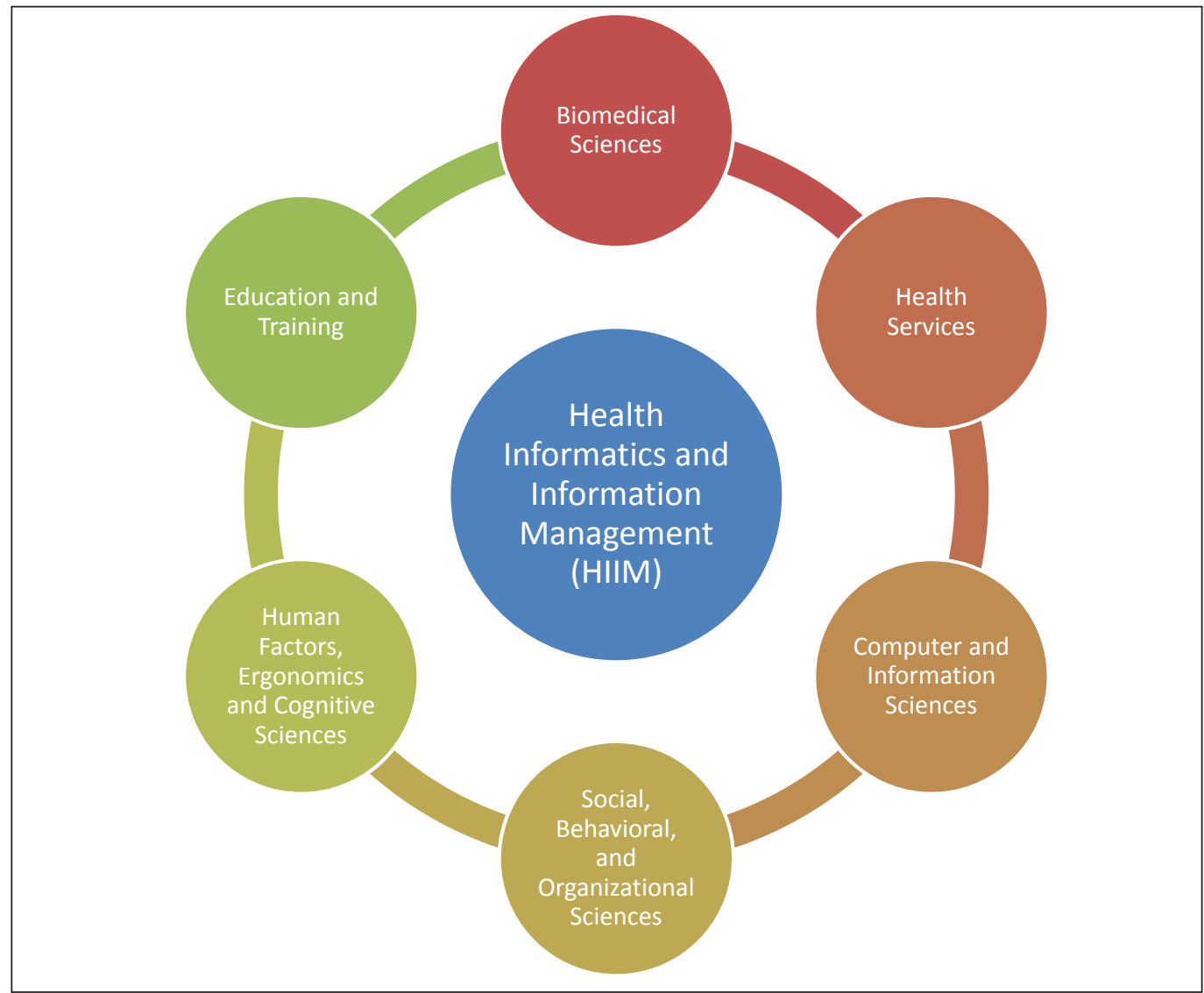

Fig. 2 Six major competency domains in health informatics and information management. ment and health informatics. 


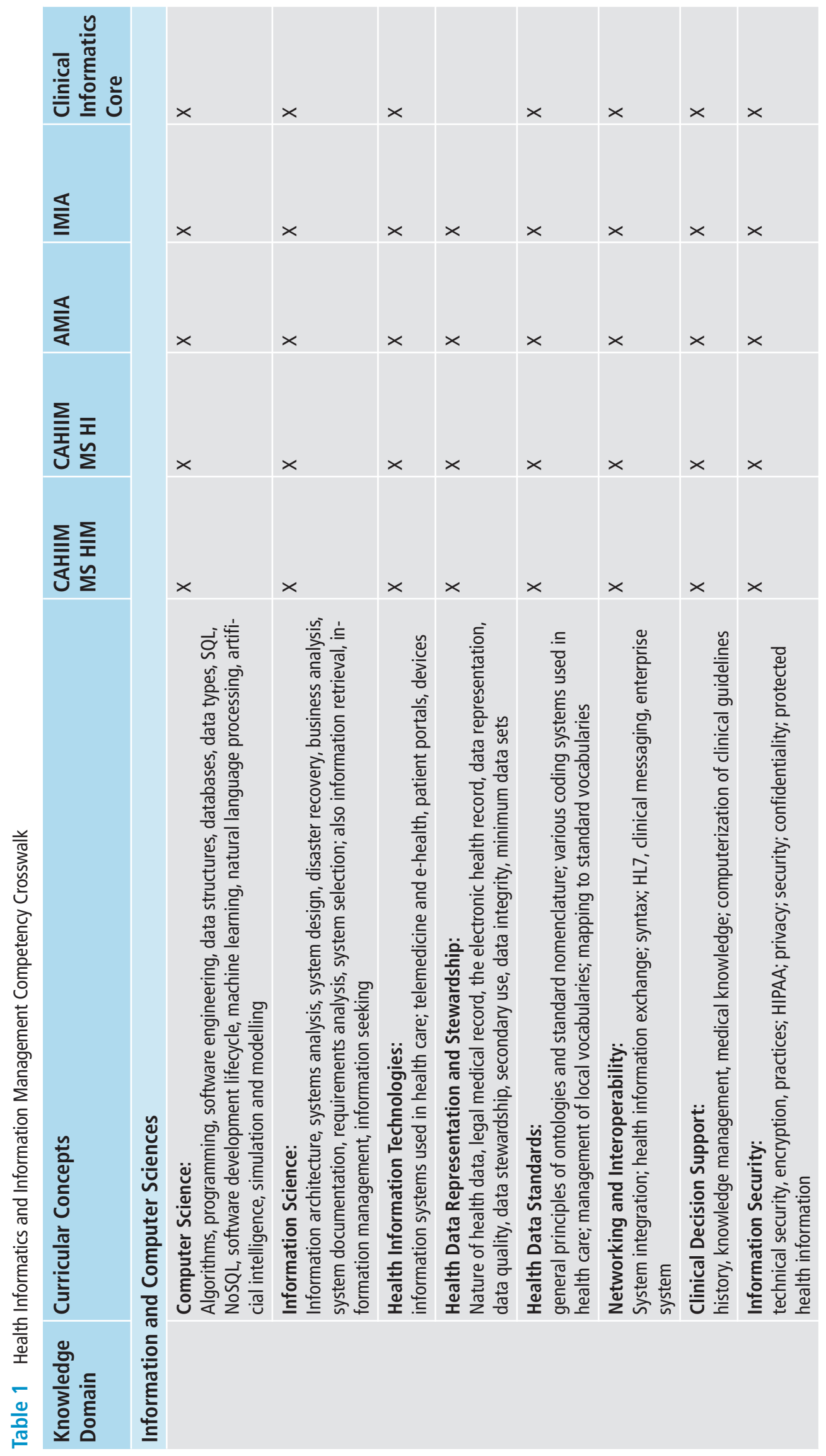



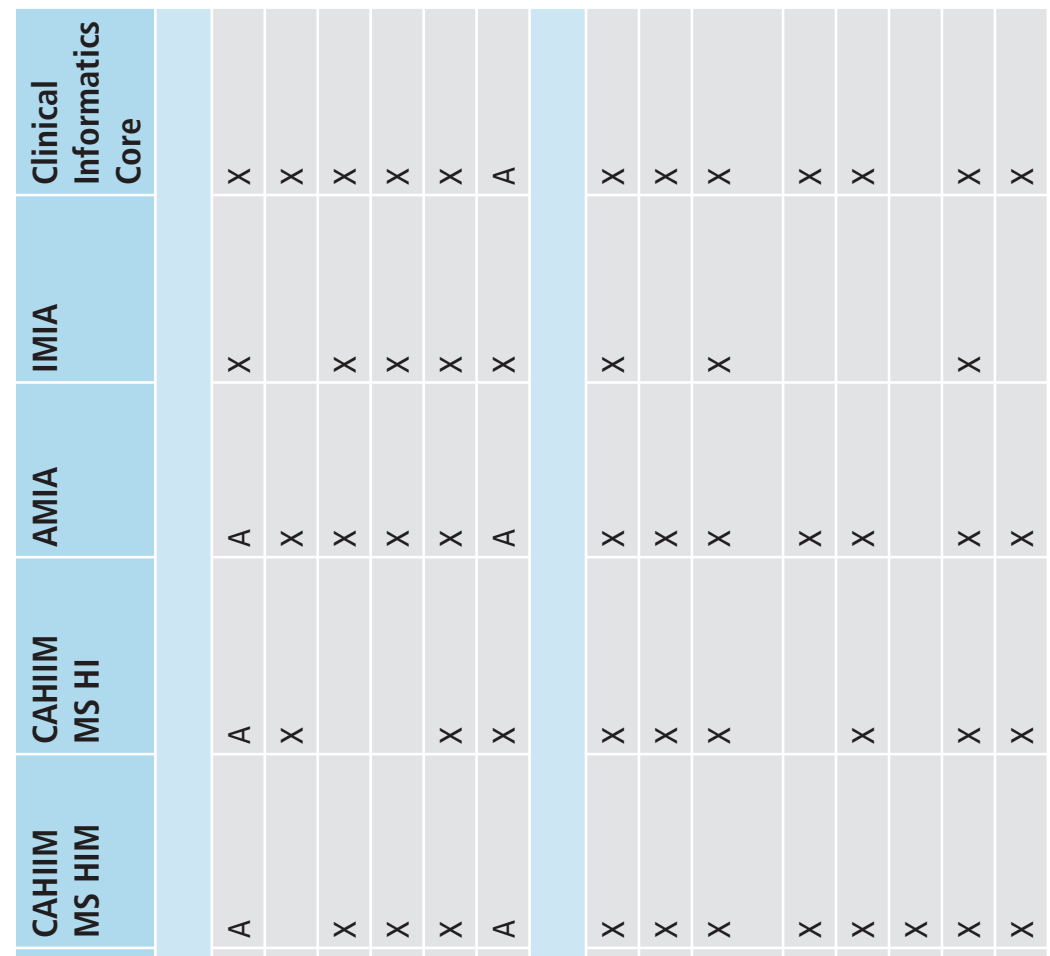

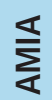

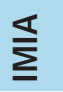
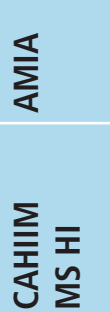

交至
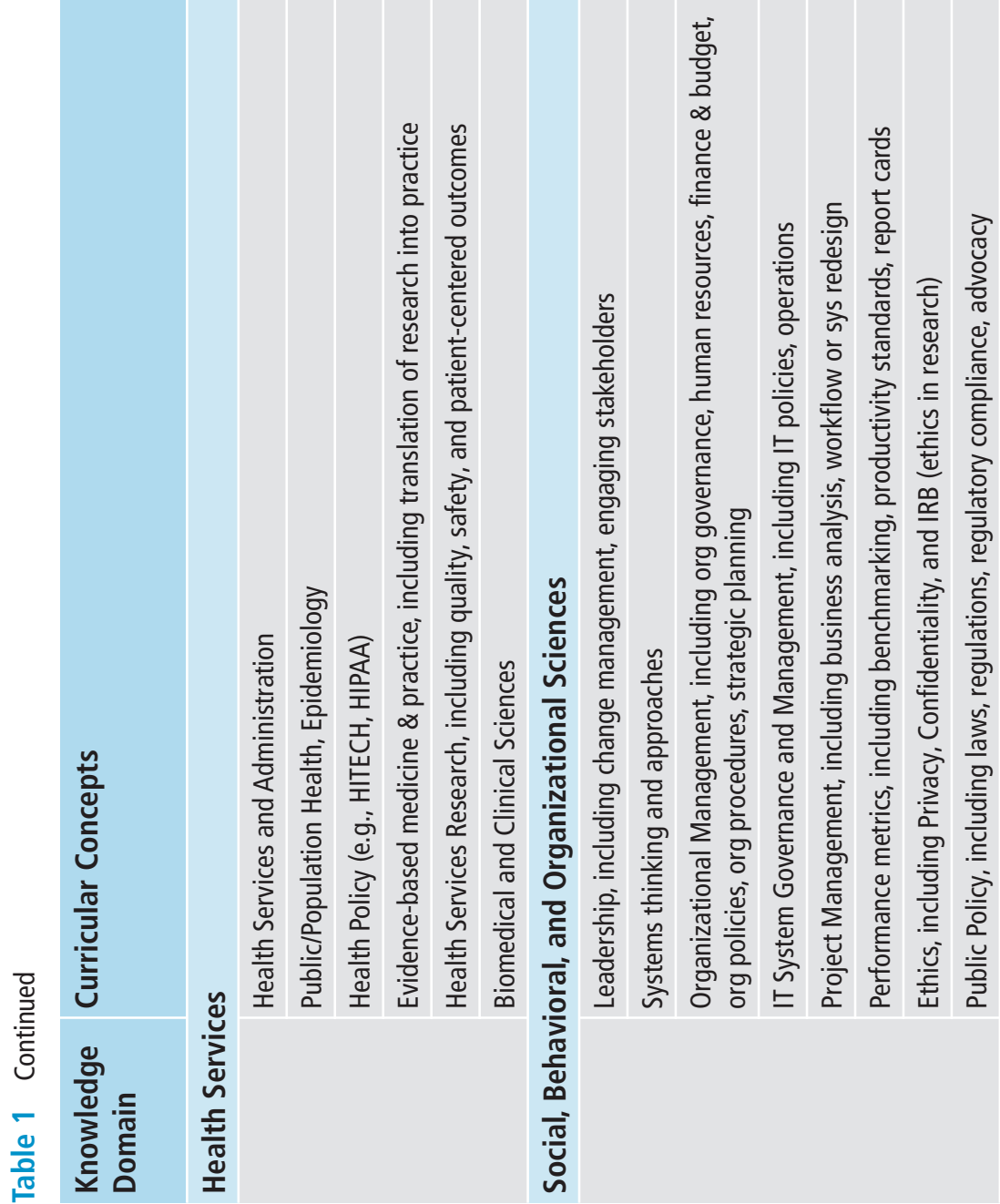


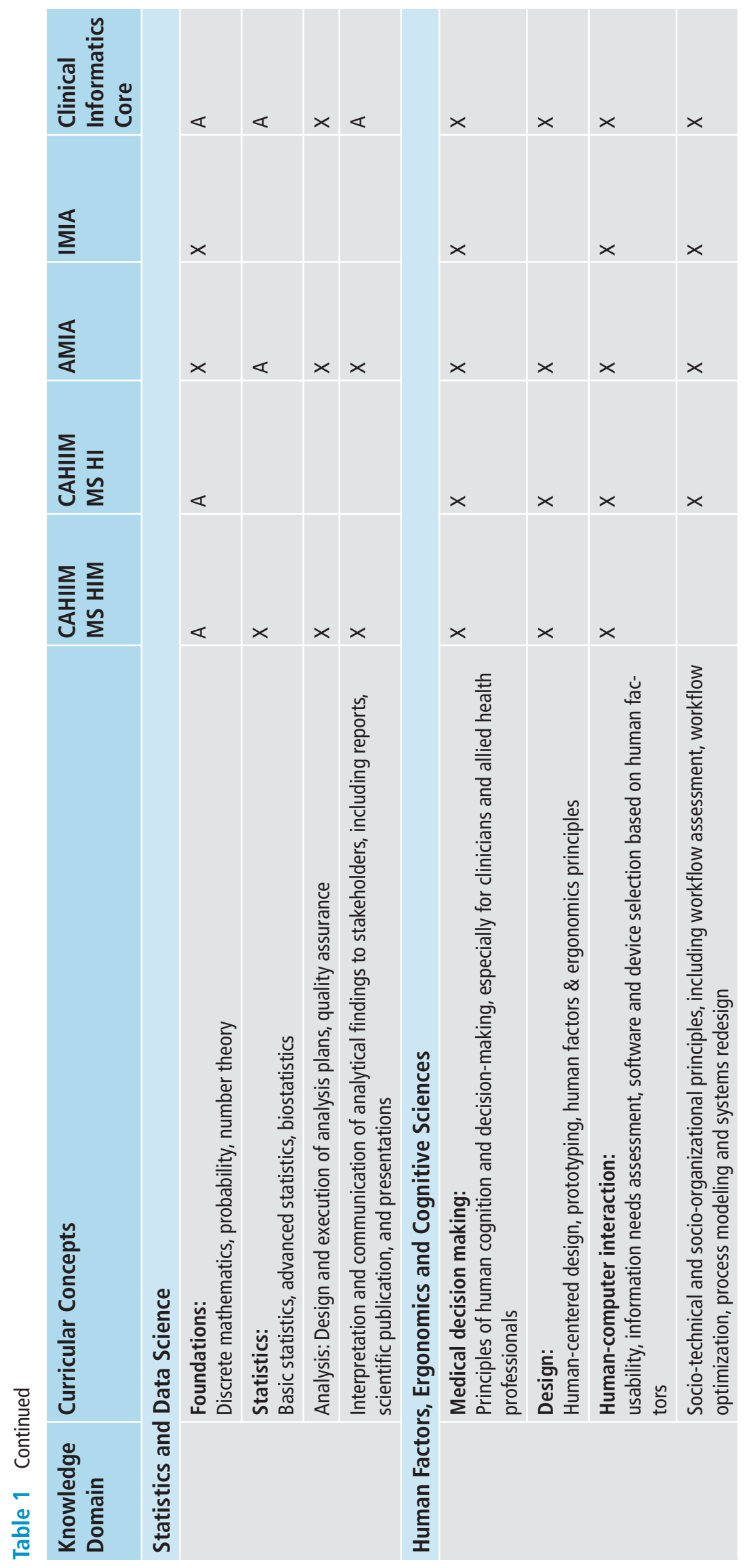




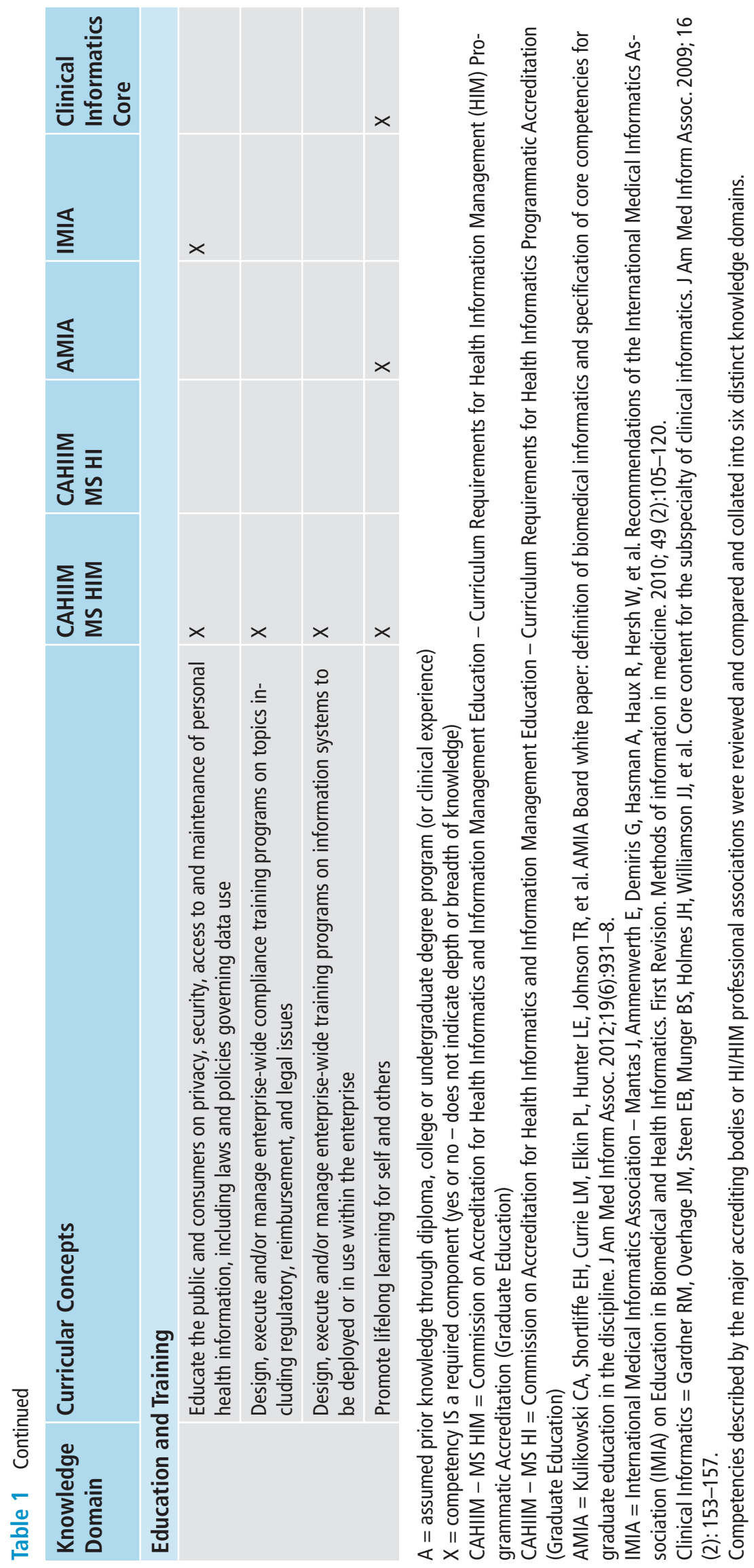




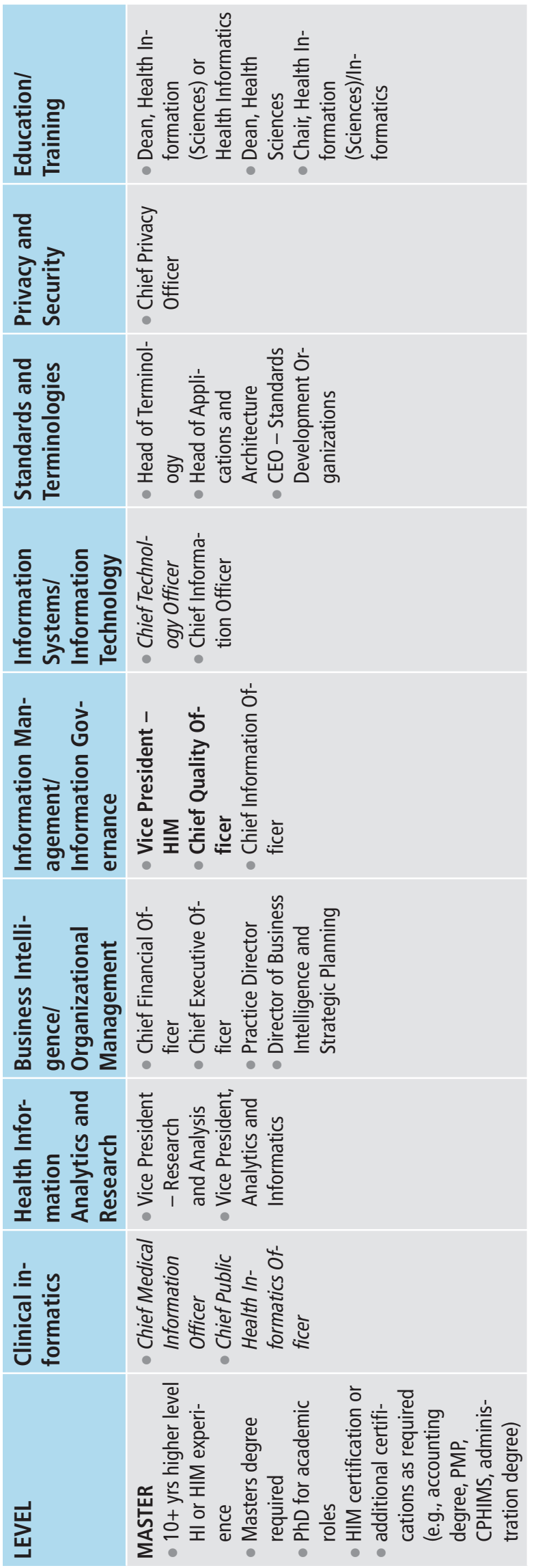




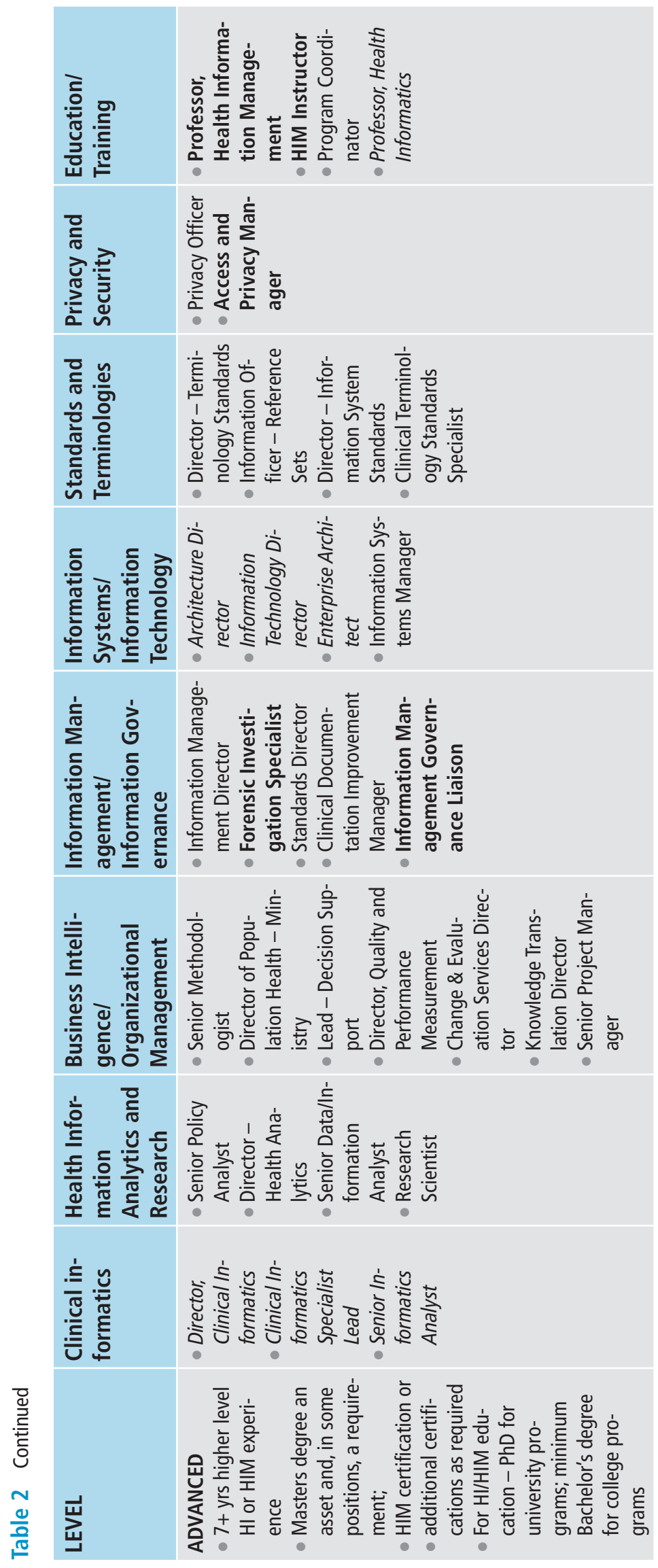



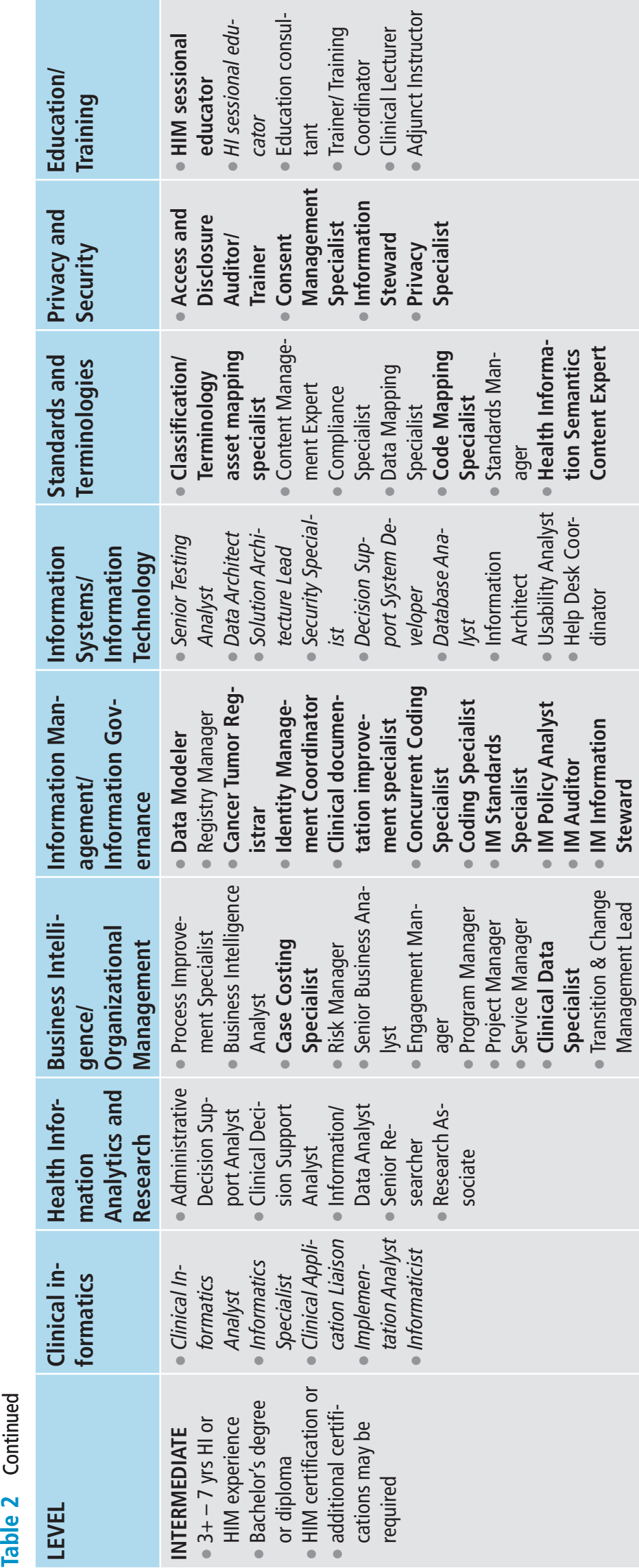

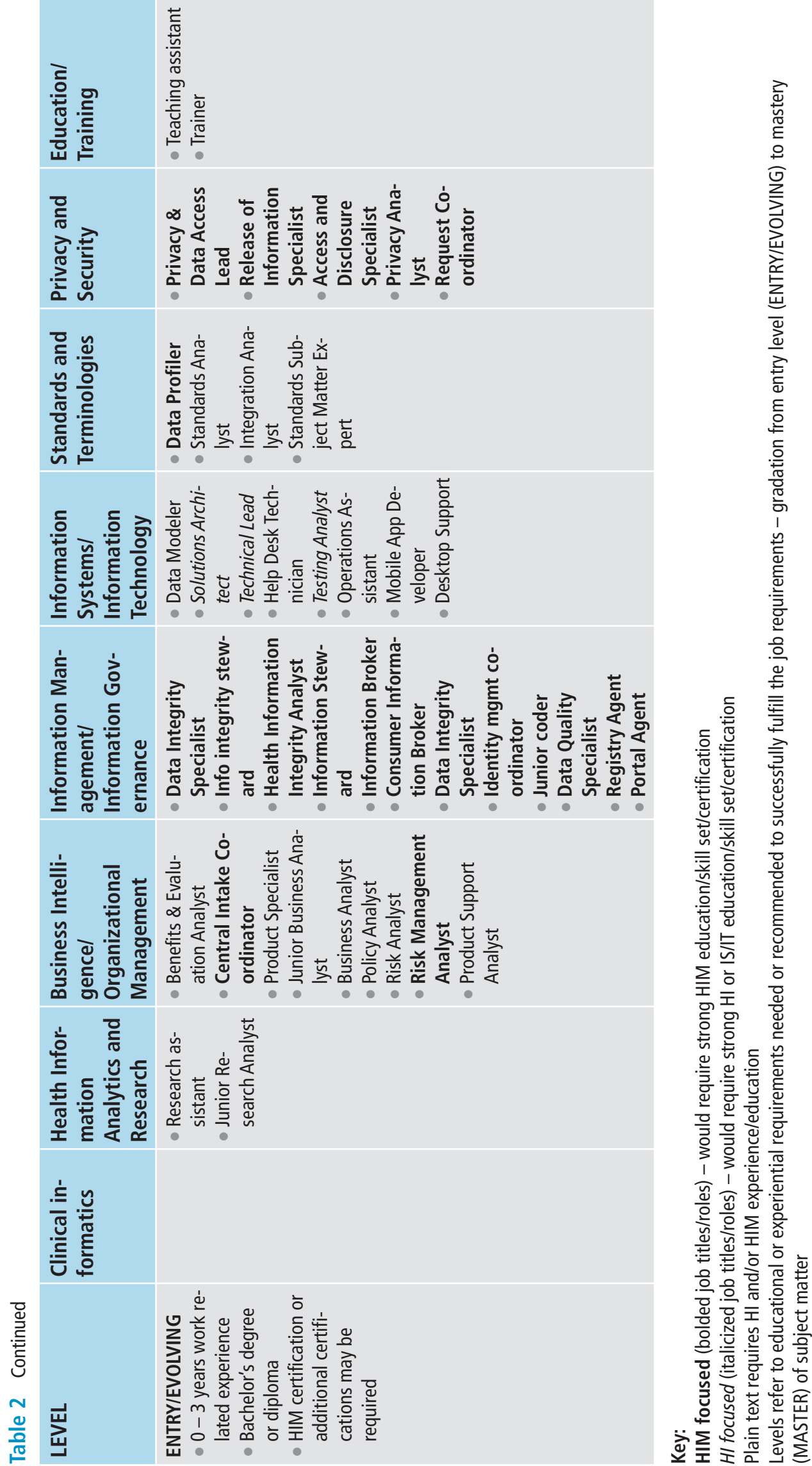


\section{References}

1. Desroches CM, Charles D, Furukawa MF, Joshi MS, Kralovec P, Mostashari F, Worzala, C., Jha, AK. Adoption of electronic health records grows rapidly, but fewer than half of US hospitals had at Least a basic system in 2012. Health Affairs (Project Hope) 2013; 32 (8): 1478-1485. Epub 2013/07/11.

2. Furukawa MF, Patel V, Charles D, Swain M, Mostashari F. Hospital electronic health information exchange grew substantially in 2008-12. Health Affairs (Project Hope) 2013; 32 (8): 1346-1354. Epub 2013/08/07.

3. Patel V, Jamoom E, Hsiao CJ, Furukawa MF, Buntin M. Variation in electronic health record adoption and readiness for meaningful use: 2008-2011. J Gen Intern Med 2013; 28 (7): 957-964. Epub 2013/02/02.

4. Canada Health Infoway. The emerging benefits of electronic medical record use in community-based care. Ontario, Canada: PwC; 2013 [cited 2014 Jun 13]; Available from: http://www.pwc.com/ca/en/healthcare/ electronic-medical-record-use-community-based-care.jhtml.

5. Centers for Medicare and Medicaid Services. Meaningful Use. Baltimore, MD: Centers for Medicare \& Medicaid Services; 2013 [updated Aug 23; cited 2013 Aug 27]; Available from: https://www.cms.gov/Regu lations-and-Guidance/Legislation/EHRIncentivePrograms/Meaningful_Use.html.

6. Furukawa MF, Poon E. Meaningful use of health information technology: evidence suggests benefits and challenges lie ahead. Am J Manag Care 2011; 17 (12 Spec No.): SP76a-SP. Epub 2012/06/27.

7. Canada Health Infoway. Progress in Canada. [cited 2014 Jun 13]; Available from: https://www.infoway-in foroute.ca/index.php/progress-in-canada.

8. Whipple EC, Dixon BE, McGowan JJ. Linking health information technology to patient safety and quality outcomes: a bibliometric analysis and review. Inform Health Soc Care 2013; 38 (1): 1-14. Epub 2012/06/05.

9. Blaya JA, Fraser HS, Holt B. E-health technologies show promise in developing countries. Health affairs (Project Hope) 2010; 29 (2): 244-251. Epub 2010/03/30.

10. Bates DW, Gawande AA. Improving safety with information technology. N Engl J Med 2003; 348 (25): 2526-2534. Epub 2003/06/20.

11. Dixon B, Grannis S. Public Health Informatics Infrastructure. In: Magnuson JA, Fu JPC, editors. Public Health Informatics and Information Systems: Springer London; 2014. p. 69-88.

12. Office of Occupational Statistics and Employment Projections. Computer and Information Systems Managers. U.S. Bureau of Labor Statistics; 2014 [updated January 8; cited 2014 May 22]; Available from: http://www.bls.gov/ooh/management/computer-and-information-systems-managers.htm.

13. Office of Occupational Statistics and Employment Projections. Medical Records and Health Information Technicians. U.S. Bureau of Labor Statistics; 2014 [updated January 8; cited 2014 May 22]; Available from: http://www.bls.gov/ooh/healthcare/medical-records-and-health-information-technicians.htm.

14.Prism Economics and Analysis. (2014). Health Informatics and Health Information Management: Human Resources Outlook 2014 - 2019. Toronto, ON: Prism Economics and Analysis.

15. Science Daily. Convergent evolution, excerpted from Wikipedia [cited 2014 Sept 8]. Available at: http://www.sciencedaily.com/articles/c/convergent_evolution.htm

16. Brodnick, MS. The health informatics and information management profession. In Abdelhak, M, Grostick, S, Hanken, MA. (editors). Health information: Management of a strategic resource, 4 th ed. St. Louis: Elsevier Saunders; 2012.

17. Crook, G, Abrams, KJ, Arnold, G. The health information management professional. In: Abrams, KJ, Gibson, CJ (editors). Fundamentals of health information management, 2nd ed. Ottawa, ON: Canadian Healthcare Association; 2013. Pp. 7-25.

18. Abrams, KJ, Gibson, CJ (editors). Fundamentals of health information management, 2nd ed. Ottawa, ON: Canadian Healthcare Association; 2013. Pg. 1

19. Fourman, M. Informatics. 2002. Edinburgh: University of Edinburgh. Informatics Research Report EDIINF-RR-0139. [Accessed 2015 Jan 10]; Available from http://www.inf.ed.ac.uk/publications/online/ 0139.pdf

20.Hersh, W. A stimulus to define informatics and health information technology. BMC Medical Informatics and Decision Making. 2009; 9: 24. doi: 10.1186/1472-6947-9-24

21. Kulikowski CA, Shortliffe EH, Currie LM, Elkin PL, Hunter LE, Johnson TR, Kalet IJ, Lenert LA, Musen MA, Ozbolt JG, Smith JW, Tarczy-Hornoch PZ, Williamson JJ. AMIA Board white paper: definition of biomedical informatics and specification of core competencies for graduate education in the discipline. J Am Med Inform Assoc 2012; 19 (6): 931-938.

22. The Science of Informatics. Bethesda, MD: American Medical Informatics Association; [cited 2014 Jul 25]; Available from: http://www.amia.org/about-amia/science-informatics.

23. Clinical Informatics. Bethesda, MD: American Medical Informatics Association; [cited 2014 Jul 25]; Available from: http://www.amia.org/applications-informatics/clinical-informatics. 
24. Magnuson JA, O’Carroll P. Introduction to Public Health Informatics. In: Magnuson JA, Fu JPC, editors. Public Health Informatics and Information Systems: Springer London; 2014. p. 3-18.

25.COACH. About Us: Vibrant, diverse community. 2014. [cited 2014 Jul 25]; Available from: http://coachorg.com/en/membership/About-Us.asp

26. HIMSS Legacy Workgroup. History of the Healthcare Information and Management Systems Society. Chicago, IL: HIMSS; 2013 [cited 2014 Jul 25]; Available from: http://www.himss.org/files/HIMSSorg/content/ files/HistoryHIMSS_January2013.pdf.

27.HIMSS Local Chapters. Chicago, IL: HIMSS; 2014 [cited 2014 Jul 25]; Available from: http://www.himss. org/Content.aspx?ItemNumber $=18685$.

28. About HIMSS Ontario Chapter. Toronto: HIMSS; [cited 2014 Jul 25]; Available from: http://www.ontario himss.org/.

29. Krumholz HM. Big data and new knowledge in medicine: the thinking, training, and tools needed for a learning health system. Health Affairs (Project Hope) 2014; 33 (7): 1163-1170.

30. Hunter K, McGonigle D, Hebda T. The integration of informatics content in baccalaureate and graduate nursing education: a status report. Nurse Educ 2013; 38 (3): 110-113.

31.AFPC (Association of Faculties of Pharmacy of Canada) \& Canada Health Infoway. Pharmacy Informatics: Entry-to-practice competencies for pharmacists. 2013. Available at: http://www.afpc.ca/info.

32. McGowan JJ, Passiment M, Hoffman HM. Educating medical students as competent users of health information technologies: the MSOP data. Studies in health technology and informatics 2007; 129 (Pt 2): 1414-1418.

33. Singh H, Spitzmueller C, Petersen NJ, Sawhney MK, Sittig DF. Information overload and missed test results in electronic health record-based settings. JAMA internal medicine 2013; 173 (8): 702-704. Epub 2013/03/06.

34. Markman M. Information overload in oncology practice and its potential negative impact on the delivery of optimal patient care. Current oncology reports 2011; 13 (4): 249-251. Epub 2011/05/12.

35.Zeldes $\mathrm{N}$, Baum N. Information overload in medical practice. The Journal of medical practice management: MPM 2011; 26 (5): 314-316. Epub 2011/05/21.

36. Bernard E, Arnould M, Saint-Lary O, Duhot D, Hebbrecht G. Internet use for information seeking in clinical practice: a cross-sectional survey among French general practitioners. Int J Med Inform 2012; 81 (7): 493-499. Epub 2012/03/20.

37. Graham-Jones, P, Jain, SH, Friedman, P, Marcotte, L, Blumenthal, D. The need to incorporate health information technology into physicians' education and professional development. Health Affairs 2012; 31 (3): 481-487. doi: 10.1377/hlthaff.2011.0423

38.Learning Outcomes for Health Information Management: Diploma/Degree Programs 2010. CHIMA, London, ON.

39. Mantas J, Ammenwerth E, Demiris G, Hasman A, Haux R, Hersh W, Hovenga, E, Lun, KC, Marin, H., Martin-Sanchez, F., Wright, G. Recommendations of the International Medical Informatics Association (IMIA) on education in biomedical and health informatics. First Revision. Methods Inf Med 2010; 49 (2): 105-120. Epub 2010/01/08.

40.IMIA Accreditation (pilot). Geneva, Switzerland: International Medical Informatics Association; 2014 [updated 16 Jan 2014; cited 2014 Jul 25]; Available from: http://www.imia-medinfo.org/new2/node/449.

41. Detmer DE, Shortliffe EH. Clinical informatics: prospects for a new medical subspecialty. JAMA 2014; 311 (20): 2067-2068. Epub 2014/05/16.

42. American Board of Preventative Medicine. Clinical Informatics Board Certification; 2013. [cited November 21, 2014]. Available at: http://www.theabpm.org/abpm_clinical_informatics.pdf

43. Gardner RM, Overhage JM, Steen EB, Munger BS, Holmes JH, Williamson JJ, Detmer DE; AMIA Board of Directors. Core content for the subspecialty of clinical informatics. J Am Med Inform Assoc 2009; 16 (2): 153-157. Epub 2008/12/17.

44. Safran C, Shabot MM, Munger BS, Holmes JH, Steen EB, Lumpkin JR, Detmer. DE, for the AMIA Board of Directors. AMIA Board White Paper: Program requirements for fellowship education in the subspecialty of clinical informatics. J Am Med Inform Assoc 2009; 16 (2): 158-166. Epub 2008/12/17.

45. Advanced Interprofessional Informatics Certification (AIIC) Program. American Medical Informatics Association; 2014. [cited November 21, 2014]. Available from: http://www.amia.org/advanced-interprofes sional-informatics-certification

46. CAHIIM, Commission on Accreditation for Health Informatics and Information Management Education - Curriculum Requirements for Health Information Management (HIM) Programmatic Accreditation (Graduate Education). Available at:

47. CAHIIM, Commission on Accreditation for Health Informatics and Information Management Education - Curriculum Requirements for Health Informatics Programmatic Accreditation (Graduate Education) 
48. Joint Work Force Task Force. Health Information Management and Informatics: Core Competencies for Individuals Working With Electronic Health Records. AHIMA and AMIA, 2008.

49. Canadian Health Information Management Association (CHIMA). Transformation of Health Information Management: The evolution of the HIM profession. 2013, London, ON.

50. American Health Information Management Association (AHIMA). Health Information Careers - Career Mapping. [cited 2014 June 29]. Available at: http://hicareers.com/CareerMap/

51.COACH: Canada's Health Informatics Association. Health Informatics Professional Core Competencies, Version 3.0. November 2012, Toronto, ON.

52. COACH: Canada's Health Informatics Association. Health Informatics Professional Career Matrix. Available at: http://www.coachorg.com/en/resourcecentre/resources/COACH-Career-Matrix.pdf

53.Dixon BE, Rosenman M, Xia Y, Grannis SJ. A vision for the systematic monitoring and improvement of the quality of electronic health data. Studies in health technology and informatics 2013; 192: 884-888. Epub 2013/08/08.

54.Dixon BE, Siegel JA, Oemig TV, Grannis SJ. Electronic health information quality challenges and interventions to improve public health surveillance data and practice. Public Health Rep 2013; 128 (6): 546-553. Epub 2013/11/02.

55. Weiskopf NG, Weng C. Methods and dimensions of electronic health record data quality assessment: enabling reuse for clinical research. J Am Med Inform Assoc 2013; 20 (1): 144-151. Epub 2012/06/27.

56. Sariyar M, Borg A, Heidinger O, Pommerening K. A practical framework for data management processes and their evaluation in population-based medical registries. Inform Health Soc Care 2013; 38 (2): 104-119. Epub 2013/01/18.

57. Fenton S, Giannangelo K, Kallem C, Scichilone R. Data standards, data quality, and interoperability (updated). J AHIMA 2013; 84 (11): 64-69. Epub 2013/12/11.

58. Clark JS, Delgado VA, Demorsky S, Dunagan EA, Eichelmann TA, Hooper LA, Landsbach G, Meehan AM, Neville DL, Nunn SL. Assessing and improving EHR data quality (updated). J AHIMA 2013; 84 (3): 48-53. Epub 2013/04/06.

59. Conestoga College. Applied health information science (Bachelor of) (Co-op). Program details. [cited 2014 Sept 8]. Available at: http://www.conestogac.on.ca/fulltime/1131C.jsp

60. University of Washington. Masters of Health Informatics \& Health Information Management. Our Program. [cited 2014 Sept 8]. Available at: http://www.health-informatics.uw.edu/our-program/

61.Louisiana Tech University. Department of Health Informatics \& Information Management. [cited 2014 Sept 8]. Available at: http://him.latech.edu/

62. The University of Tennessee Health Science Center. Health Informatics \& Information Management. [cited 2014 Sept 8]. Available at: http://www.uthsc.edu/health-professions/him/index.php

63. University of Illinois at Chicago. Masters in Health Informatics \& Health Information Management Degrees. [cited 2014 Sept8]. Available at: http://healthinformatics.uic.edu/

64. Indiana University-Purdue University Indianapolis. School of Computing and Informatics. Department of BioHealth Informatics. [cited 2104 Sept 8]. Available at: http://soic.iupui.edu/departments/biohealth/

65. Oregon Health \& Science University (OHSU). Biomedical Informatics Educational Programs, 2014. [Accessed 2014 Nov 14] Available at: http://www.ohsu.edu/xd/education/schools/school-of-medicine/depart ments/clinical-departments/dmice/educational-programs/index.cfm

66. Health IT Certification. [cited 2014 Sept 8]. Available at: http://www.healthitcertification.com/index.html 